\title{
The formation and growth of ultrafine particles in two contrasting environments: a case study
}

\author{
Sobhan Kumar Kompalli ${ }^{1}$, S. Suresh Babu ${ }^{1}$, K. Krishna Moorthy ${ }^{1, *}$, Mukunda M Gogoi ${ }^{1}$, Vijayakumar S Nair ${ }^{1}$, \\ and Jai Prakash Chaubey ${ }^{1}$ \\ ${ }^{1}$ Space Physics Laboratory, Vikram Sarabhai Space Centre, Thiruvananthapuram, 695 022, India \\ * currently at: ISRO Headquarters, Bangalore, 560 231, India
}

Correspondence to: S. Suresh Babu (s_sureshbabu@vssc.gov.in, sureshsplvssc@gmail.com)

Received: 24 June 2013 - Revised: 21 April 2014 - Accepted: 9 May 2014 - Published: 22 July 2014

\begin{abstract}
Formation of ultrafine particles and their subsequent growth have been examined during new particle formation (NPF) events in two contrasting environments under varying ambient conditions, one for a tropical semiurban coastal station, Trivandrum, and the other for a highaltitude free-tropospheric Himalayan location, Hanle. At Trivandrum, NPF bursts took place in the late evening/night hours, whereas at Hanle the burst was a daytime event. During the nucleation period, the total number concentration reached levels as high as $\sim 15900 \mathrm{~cm}^{-3}$ at Trivandrum, whereas at Hanle, the total number concentration was $\sim 2700 \mathrm{~cm}^{-3}$, indicating the abundant availability of precursors at Trivandrum and the pristine nature of Hanle. A sharp decrease was associated with NPF for the geometric mean diameter of the size distribution, and a large increase in the concentration of the particles in the nucleation regime $\left(D_{\mathrm{p}}<25 \mathrm{~nm}\right)$. Once formed, these (secondary) aerosols grew from nucleation (diameter $D_{\mathrm{p}}<25 \mathrm{~nm}$ ) to Aitken $\left(25 \leq D_{\mathrm{p}} \leq 100 \mathrm{~nm}\right)$ regime and beyond, to the accumulation size regimes $\left(100 \leq D_{\mathrm{p}} \leq 1000 \mathrm{~nm}\right)$, with varying growth rates (GR) for the different size regimes at both the locations. A more rapid growth $\sim 50 \mathrm{~nm} \mathrm{~h}^{-1}$ was observed at Trivandrum, in contrast to Hanle where the growth rate ranged from 0.1 to $20 \mathrm{~nm} \mathrm{~h}^{-1}$ for the transformation from the nucleation to accumulation - a size regime that can potentially act as cloud condensation nuclei (CCN). The faster coagulation led to lifetimes of $<1 \mathrm{~h}$ for nucleation mode particles.
\end{abstract}

Keywords. Atmospheric composition and structure (aerosols and particles)

\section{Introduction}

Secondary aerosol formation and their subsequent growth to higher size ranges are important mechanisms in aerosol dynamics controlling aerosol population and size distributions in the atmosphere. To assess the impact of secondary aerosol on the global climate it is necessary to understand the mechanisms involved in the formation and evolution of secondary aerosols (from precursor gases) and to follow their growth to larger sizes where they are optically active, efficiently scatter incoming solar radiation, as well as act as cloud condensation nuclei and modify cloud radiative properties. Secondary aerosol production via the nucleation of gas-phase reaction products of precursors is one of the most significant sources of fine and ultrafine particles in the atmosphere (Kulmala et al., 2004; Kulmala and Kerminen, 2008). Several studies have revealed that new particle formation (NPF) through nucleation and subsequent growth to larger sizes under diverse atmospheric conditions occurs frequently in the Earth's atmosphere (Weber et al., 1999; Kulmala et al., 2004; Kulmala and Kerminen, 2008; O'Dowd and Hoffmann, 2005; Curtius, 2006, and references therein). Despite these previous works, it remains one of the intensely investigated topics due to the limitations existing in our understanding of NPF, due to the spatial inhomogeneity of aerosol sources and atmospheric chemistry, the mechanisms that control aerosol dynamics, and the prevailing meteorology that determines the frequency and intensity of these events. The decoupling of the nucleation of initial clusters and their growth to detectable sizes poses a problem for predicting aerosol dynamics, making experimental observations of nucleation and growth in various 
environments an essential requirement for understanding the phenomenon better (Curtius, 2006).

While high-altitude locations at free tropospheric heights, which act as reservoirs for several gaseous species, witness NPF events on the synoptic scale through gas-particle conversion under favourable conditions, such as the availability of abundant UV radiation and moisture (Weber et al., 1995, 1999; Weingartner et al., 1999; Shaw, 2007; Nishita et al., 2007; Moorthy et al., 2011), urban and coastal environments have been observed to be potentially important sources of highly intense but localised aerosol formation bursts (O'Dowd et al., 1998a, b, 1999, 2002b; Väkevä et al., 2000; Stanier et al., 2004; Ahlm et al., 2012) where abundant availability of moisture and volatile gases (anthropogenic, biogenic, and urban activities) exists. Distinctiveness in growth dynamics for these various environmental conditions is worth investigating. One important aspect of NPF is its dependence on available UV radiation. While most daytime NPF events involve the photochemistry of precursors, nighttime NPF is quite infrequent although not uncommon (Rissler et al., 2006; Russel et al., 2007; Lee et al., 2008). As such, nighttime NPF events are less explored as compared to daytime occurrences. This is more so over the Indian region.

In this work we present two case studies of ultrafine particle formation and growth over two distinct environments: (i) a late evening/nighttime event at a tropical coastal semi-urban station, Trivandrum; and (ii) a daytime event at an extra-tropical high-altitude, dry, free-tropospheric, Himalayan location, Hanle. In addition to these characteristics, we have used these observations to estimate the growth rates in different size domains (due to coagulation and condensation) and the resulting changes in aerosol size distribution.

\section{Experimental details}

The locations of the study, Trivandrum and Hanle, shown in Fig. 1, are part of a national network of aerosol observatories (ARFINET) under the Aerosol Radiative Forcing over India (ARFI) project of the Indian Space Research Organisation's Geosphere Biosphere Programme, which aims to characterise the aerosol environment over the Indian region. Trivandrum $\left(8.55^{\circ} \mathrm{N}, 76.97^{\circ} \mathrm{E}, 3 \mathrm{~m}\right.$ a.m.s.l. $)$ is a tropical coastal semi-urban station located at the southwestern tip of peninsular India. The observation site (located within the Thumba Equatorial Rocket Launching Station) is characterised by a flat coastal terrain with moderate vegetation, and is $500 \mathrm{~m}$ due east of the Arabian Sea coast, $\sim 2 \mathrm{~km}$ due west of a national highway, and $10 \mathrm{~km}$ northwest of the urban area of Trivandrum. The area is free from the proximity of any major industrial and urban activities. The local coastline is along the $325-145^{\circ}$ azimuth. Being located within the rocket launch station, a restricted area, human activity is highly subdued for $\pm \sim 3 \mathrm{~km}$ parallel to the coast and approximately

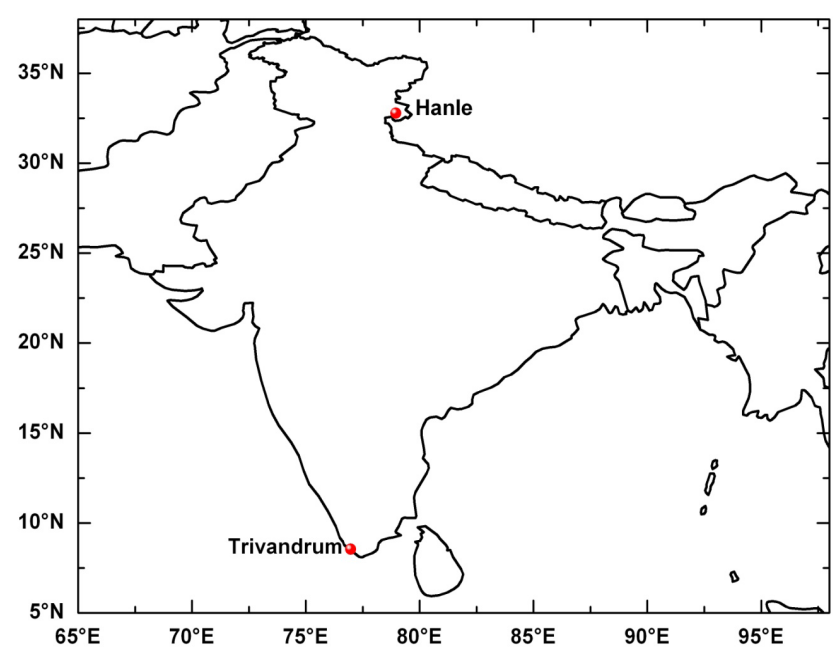

Figure 1. Map showing the geographical location of (a) Trivandrum - a tropical coastal station in peninsular India - and (b) Hanle - a high-altitude location in the western Trans-Himalayas.

$1 \mathrm{~km}$ across the measurement site (more details on the station are available in Pillai and Moorthy, 2001; Babu and Moorthy, 2001). Major atmospheric meteorological processes important to this location are the synoptic-scale general circulation patterns associated with the Indian monsoon system (Krishna Moorthy et al., 2007; Suresh Babu et al., 2007), which is seasonal, and mesoscale land-sea breeze activity due to coastal proximity (Pillai and Moorthy, 2001, and references therein), which is conspicuous in the December to April months.

In sharp contrast, Hanle $\left(32.78^{\circ} \mathrm{N}, \quad 78.96^{\circ} \mathrm{E}\right.$; $4520 \mathrm{~m}$ a.m.s.l) is an extra-tropical high-altitude, nearpristine location in the western trans-Himalayas and southwest of the Tibetan plateau (Verma et al., 2009; Moorthy et al., 2011; Babu et al., 2011). Measurements were made from a mountaintop observatory, $\sim 300 \mathrm{~m}$ above the surrounding sparsely populated valley region. With completely subdued local activity, and being located far from major anthropogenic pollution source regions, the location is considered to be a virtual free troposphere location. The mesoscale circulation of relevance at Hanle is the mountain-valley breeze circulation characteristic of such locations (Shaw, 2007; Sellegri et al., 2010; Bonasani et al., 2010). More details regarding the location are available in earlier publications (Moorthy et al., 2011; Babu et al., 2011).

Aerosol number size distribution measurements were performed at both the locations using a Sequential Mobility Particle Sizer + Counter (SMPS + C) (make: GRIMM, www.grimm-aerosol.com) (Helsper et al., 2008). The SMPS system consists of a differential mobility analyser (DMA) that segregates particles according to their electrical mobility (Winkelmaier et al., 1991; Collins et al., 2004, and references therein), and then transfers the narrow monodisperse particles to a condensation particle counter (CPC) (GRIMM 5.400) for counting. Before passing to the DMA classifier, 
aerosols are brought to a well-defined equilibrium charge distribution by an Americium (AM241) source. Classification of the particles occurs in the electrostatic electric field in the annulus between the inner and outer electrodes of the DMA. The DMA was operated with sheath and sample airflow rates of 2 and 0.2 liters per minute (Lpm), respectively at Hanle (these were 3 and $0.3 \mathrm{Lpm}$ at the coastal site) while the voltages varied from 0 to 10000 volts. The size distribution of the particles was measured with a stepwise change of the DMA voltage. The near-monodisperse aerosol flow from the DMA was counted by the CPC. The basic working principle is that the aerosol flow initially passes over a warm reservoir of the working fluid (N-Butanol, Butyl alcohol $\mathrm{C}_{4} \mathrm{H}_{9} \mathrm{OH}$ ), where it becomes saturated in a condensable vapour. During subsequent cooling in the condenser, the vapour becomes supersaturated, causing the particles to grow into large droplets that are individually detected by light scattering. This SMPS $+\mathrm{C}$ system measures the number concentration with a counting accuracy of $10 \%$ in the range $0-10^{7} \mathrm{~cm}^{-3}$ and $5 \%$ accuracy up to $2 \times 10^{5} \mathrm{~cm}^{-3}$.

During the study period, data were collected using long DMA classifiers that spanned the particle size diameter range from 10 to $875 \mathrm{~nm}$ at Trivandrum (for a period of 30 days in campaign mode from May to June 2009), whereas the size range was 16 to $1364 \mathrm{~nm}$ at Hanle (after correcting for the lower ambient pressure at Hanle that resulted in a flow modification) and the size distribution was segregated into 44 size classes. At both locations, sample air was drawn into the instrument from an inlet at $2 \mathrm{~m}$ above the ground using a $1 \mathrm{~m}$ electrically conductive resinous tube. Simultaneous high-resolution measurements of meteorological parameters were performed at both locations using automatic weather stations.

In the following, we present two cases of NPF and growth that occurred during the summer monsoon season - the first case is from Trivandrum, a "late evening/nighttime" NPF event that occurred from 4 to 5 June 2009. The second case is from Hanle, a daytime NPF event that occurred from 10 to 12 August 2010. These are taken as an illustration of the variety of aerosol formation and transformation processes as well as the role of meteorological and mesoscale circulation in these. The criteria previously prescribed by Dal Maso et al. (2005) were adopted in order to identify the "new particle formation event", which is as follows: (1) a distinctly new mode of particles must appear in the size distribution, (2) the mode must begin in nucleation mode, (3) the mode must prevail over a time span of few hours, and (4) the new mode must show signs of "growth". It should be kept in mind that the nucleation mode described in this work is not the nascently nucleated particle mode, but an already grown one that existed within the detection limit of the instrument $(10 \mathrm{~nm}$ or more). It should also be kept in mind that at these locations, the observations were carried out in campaign mode; NPF and growth events also conspicuously occurred rather infrequently and as such, the case study involves limited data.

\section{Results and discussion}

\subsection{Case 1: the coastal semi-urban location}

The first case at Trivandrum consisted of two conspicuous NPF bursts that occurred during the period from 12:00 on 4 June 2009 to 06:00 Indian Standard Time (IST) (IST $=\mathrm{UT}+05: 30 \mathrm{~h}$ ) on 5 June 2009, the second one occurring around midnight. During this period the ambient temperature was moderate $\left(26-32^{\circ} \mathrm{C}\right)$, and low wind speeds $\left(<3 \mathrm{~m} \mathrm{~s}^{-1}\right)$ prevailed with considerably high relative humidity $(\mathrm{RH})(70<\mathrm{RH}<92 \%)$ throughout the event duration. Time evaluation of aerosol number size distribution $\left(\mathrm{d} N / \mathrm{d} \ln D_{\mathrm{p}}\right)$ during the events is shown in Fig. 2, while Fig. 3 displays the temporal variation of the number concentrations; the total number concentration $\left(N_{\mathrm{t}}\right)$, the number concentration of the nucleation mode $\left(N_{\text {nuc }}\right)$ (particle diameter $\left.D_{\mathrm{p}}<25 \mathrm{~nm}\right)$, the Aitken mode $\left(N_{\text {ait }}\right)$ $\left(25 \mathrm{~nm}<D_{\mathrm{p}}<100 \mathrm{~nm}\right)$, and the accumulation mode $\left(N_{\mathrm{acc}}\right)$ $\left(D_{\mathrm{p}}>100 \mathrm{~nm}\right)$ particles.

\subsubsection{Number concentrations}

The two conspicuous nucleation and growth events are identified on the $x$ axis as thick red shades in Fig. 2. First nucleation burst was seen from 16:00 to 19:00 on 4 June 2009 which started at $\sim 16: 30$ peaked at $\sim 18: 00$, and then gradually subsided. The second event occurred during 00:00 to 03:00 on 5 June 2009 and was a totally nighttime event. During the subsequent $2-3 \mathrm{~h}$ period of the first burst, particle growth from the nucleation mode to larger sizes is clearly revealed. As seen from Fig. 3, prior to the nucleation burst, total number concentrations $\left(N_{\mathrm{t}}\right)$ were benign in the range of $2000-4000 \mathrm{~cm}^{-3}$, with a mean value of approximately $2350 \pm 850 \mathrm{~cm}^{-3}$ (as expected for a suburban coastal location). During the nucleation burst $N_{\mathrm{t}}$ reached values as high as $15900 \mathrm{~cm}^{-3}$, indicating a $\sim 5$-fold increase in total particle abundance. This resulted mainly, if not entirely, due to the large increase in $N_{\text {nuc }}$ as seen by the curve (marked $N_{1}$ ) in Fig. 3, and indicates the strength of the event and its nascent nature.

By examining the various size regimes, we notice that the nucleation regime remained benign from 12:00 noon on 4 June, with a concentration of $\sim 350 \mathrm{~cm}^{-3}$, suggesting fewer pre-existing ultrafine particle concentrations. During the first burst, the average $N_{\text {nuc }}$ increased by $\sim 20$ times (with concentrations of nearly $\sim 6800 \mathrm{~cm}^{-3}$, marked as $N_{1}$ in the pink curve with open circles in Fig. 3), indicating the sharpness of the event that lasted for approximately 2 h (centered $\sim$ 18:00 LT, Fig. 3) and lasted until $\sim 21: 00$. This was followed by another burst that was centered at $\sim$ 01:00 that lasted for approximately two hours. It was a weaker and shorter-lived event (compared to the first burst) during which the nucleation number concentration reached $\sim 6000 \mathrm{~cm}^{-3}$ at its peak (marked as $N_{2}$ in Fig. 3) from a 


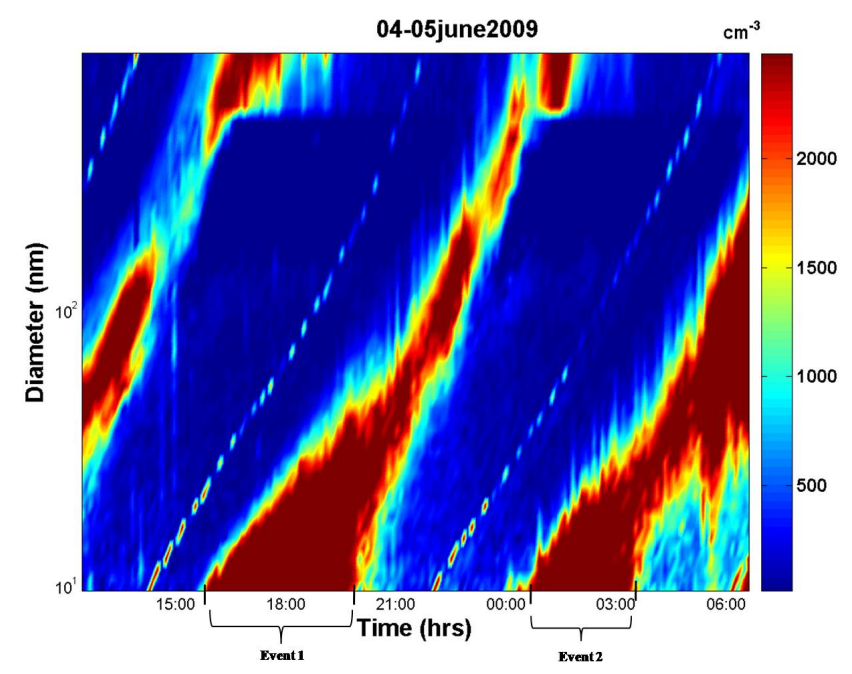

Figure 2. Temporal variation of the aerosol number size distribution $\left(\mathrm{d} N / \mathrm{d} \ln D_{\mathrm{p}}\right)$ during the event at Trivandrum (between 11:00 of 4 June 2009 and 06:00 of 5 June 2009 local time). New particle formation and growth to larger sizes are clearly indicated by the red shade "growth banana".

value of $\sim 250 \mathrm{~cm}^{-3}$ before the event. Peaks in the Aitken and accumulation regimes occurred later for both events, as follows: at $\sim 21: 30\left(A_{1}\right)$ (with $N_{\text {aitk }} \sim 1530 \mathrm{~cm}^{-3}$ ) for the first and at $\sim$ 05:00 $\left(A_{2}\right)$ (with $N_{\text {aitk }} \sim 4000 \mathrm{~cm}^{-3}$ for the first in Aitken mode, and a bit later, $\sim 22: 30\left(\mathrm{AC}_{1}\right.$, with $\left.N_{\text {acc }} \sim 2000 \mathrm{~cm}^{-3}\right)$ and $\sim 06: 00\left(\mathrm{AC}_{2}\right.$, with the $N_{\text {acc }}$ reaching $\sim 3000 \mathrm{~cm}^{-3}$ ) in accumulation mode. By this time the nucleation number concentration had fallen to less than $1 / 10$ th of its peak value, indicating that most of these particles grew to larger sizes, giving rise to signatures in the Aitken and accumulation regimes.

As seen in Figs. 2 and 3, the nucleation burst was immediately followed by the rapid growth to larger sizes. As this process gained momentum, $N_{\text {nuc }}$ and $N_{\mathrm{t}}$ began to decrease, more rapidly after a size transformation occurred in the Aitken regime and above. During this growth period, almost 10-fold increases in the accumulation number concentration $\left(N_{\text {acc }}\right)$ occurred $\left(N_{\text {acc }}\right.$ reached as high as $\sim 2000 \mathrm{~cm}^{-3}$ from its concentration of $\sim 200 \mathrm{~cm}^{-3}$ ) prior to the event with a rapid drop in $N_{\text {nuc }}$ (as well as $N_{\mathrm{t}}$ ), indicating a significant decrease in ultrafine particle concentration (possibly lost due to growth to larger sizes). The values are quite logical for the case of "coagulation", as e.g. the requirement of volume conservation demands that eight particles should be lost at a given radius " $\mathrm{r}$ ", in order to yield (by growth) one particle at size "2r" if the particles are spherical. Thus, the loss in concentration at the smaller radii must be more rapid than the gain at the larger radii.

\subsubsection{Number size distributions}

Based on the above, we have examined how the number size distributions (NSD) were impacted as a result. In Fig. 4, the

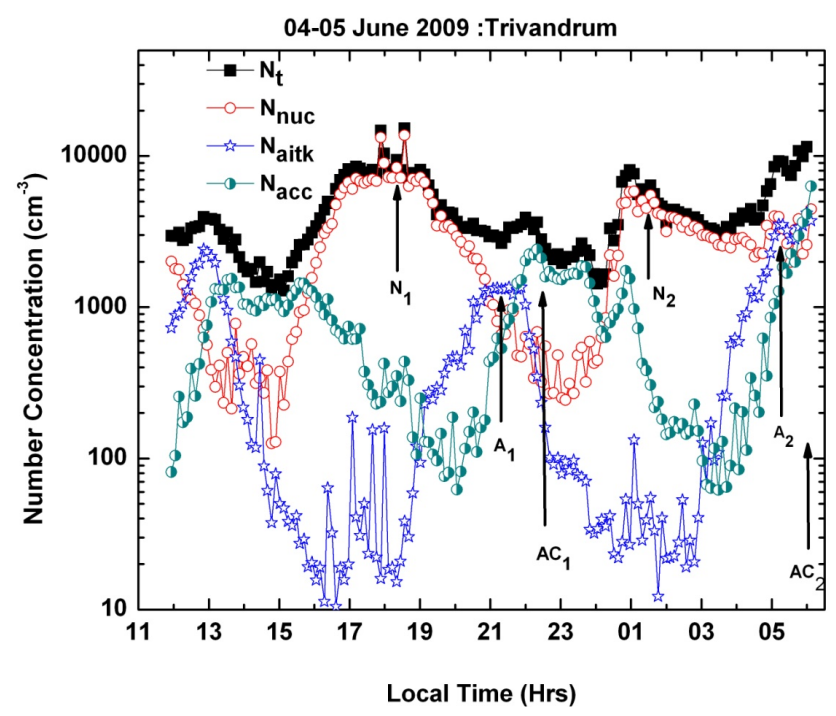

Figure 3. Temporal variation in aerosol number concentration during the event (between 11:00 of 4 June 2009 and 06:00 of 5 June 2009 local time) at Trivandrum: total number concentration $\left(N_{\mathrm{t}}\right)$, number concentration of nucleation mode $\left(N_{\text {nuc }}\right)$ (particle diameter $\left.D_{\mathrm{p}}<25 \mathrm{~nm}\right)$, Aitken mode $\left(N_{\text {ait }}\right)\left(25 \mathrm{~nm}<D_{\mathrm{p}}<100 \mathrm{~nm}\right)$ and accumulation mode $\left(N_{\mathrm{acc}}\right)\left(D_{\mathrm{p}}>100 \mathrm{~nm}\right)$ particles. The peaks are identified in the vertical arrows with symbols $N$ (nucleation), A (Aitken) and AC (accumulation).

hourly mean number size distributions $\left(\mathrm{d} N / \mathrm{d} \ln D_{\mathrm{p}}\right)$ prior to and during the events are displayed (in the panels from left to right). Prior to the first NPF event (left panel) the size distributions were eventless, with benign concentrations and modes at $\sim 100 \mathrm{~nm}$, and a still weaker mode at $\sim 300$ to $500 \mathrm{~nm}$. During event 1 (the middle panel of Fig. 4), an "open mode" began to appear (at approximately 16:00) at the lower end of the size spectrum, indicating the occurrence of an NPF burst, where freshly nucleated particles were still at sizes smaller than the smallest detectable size limit of the DMA. As the event strengthened and time progressed, the open mode also strengthened $(\sim 17: 00)$. With subsequent growth to larger sizes, the mode gradually evolved from 18:00 onward and became more and more conspicuous, with the open mode gradually closing with time, following almost all of the criteria used to identify NPF (Dal Maso et al., 2005). Synchronised with this growth, most likely as a result of coagulation, there was a steady and sharp decrease in particles for sizes lower than the mode, as well as a consequent sharp decrease in the total concentration and the mode amplitude. The processes continued until $\sim 20: 00$. Subsequently, it appears that condensational growth took over, such that the shape of the size distribution remained more or less intact, but the mode shifted to larger sizes (typical of condensational growth, Shettle and Fenn, 1979). The second event also presented a similar picture (seen in the right panel of Fig. 4). 


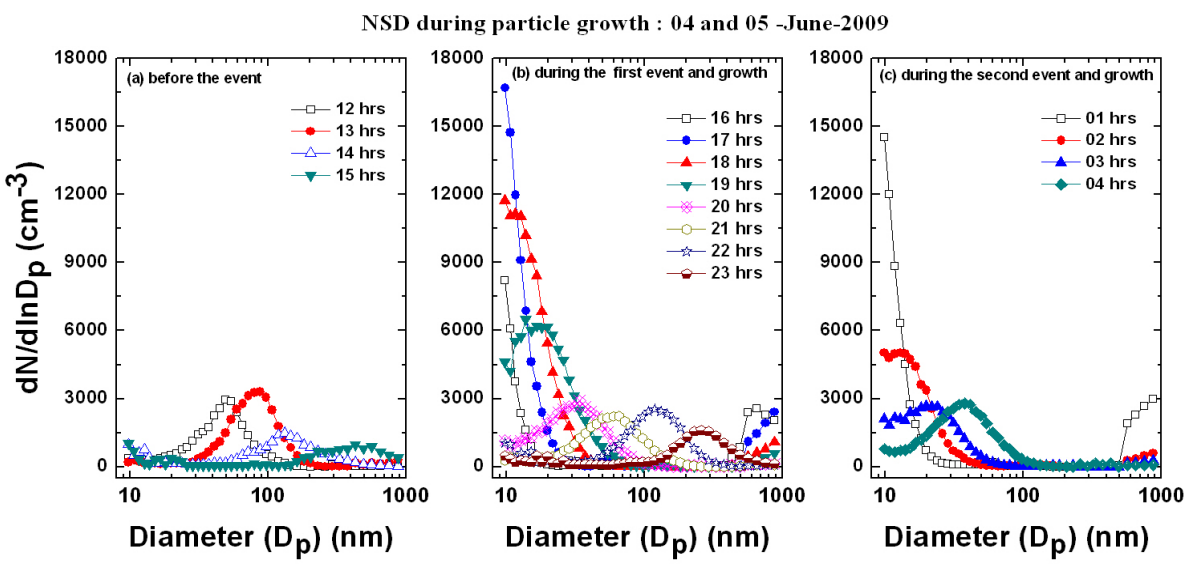

Figure 4. Temporal evolution of hourly mean aerosol number size distribution: (a) before the event, (b) during the first event and growth, and (c) during the second event and growth at Trivandrum.

\subsubsection{Limiting processes}

The formation of nucleation mode particles and their subsequent growth from initial clusters (typically assumed to be $\sim 1 \mathrm{~nm}$ ) to detectable sizes depends on the concentration of precursor gases (e.g. Stanier et al., 2004; McMurry and Eisele, 2005). It is known that new particle formation can occur as a result of the binary or ternary nucleation of non- or low-volatile gas-phase species emitted from either biogenic or anthropogenic sources, followed by the growth of these clusters into small particles (Holmes, 2007; Smorodin and Hopke, 2006). Several mechanisms have been proposed to explain this process in the atmosphere (Kulmala et al., 2001, 2004; Kulmala and Kerminen, 2008; Wang et al., 2010; Riipinen et al., 2012). It may be noted that the growth of ultrafine particles or clusters is possible, also through heterogeneous chemistry involving the precursors and pre-existing particles, which is not NPF but a limiting process. Both of these processes would have contributed to the observed changes in size distribution at Trivandrum, the possibility which we examined in detail in this study.

If due to heterogeneous chemistry, precursor gases condense on pre-existing particles with a sufficiently large condensational surface area, the process would then serve as a condensation sink for limiting the concentration of ultrafine particles, and, thus, the nucleation burst. The diameter of the particle increases and the size distribution changes its shape whenever vapour condenses on the particles. The condensation sink (CS) thus indicates how rapidly condensable vapour molecules condense on pre-existing particles (considering the entire particle size distribution), and is related to the molecular diffusivity $(D)$, the particle diameter, and the size distribution functions through the following expression:

$\mathrm{CS}=2 \pi \mathrm{D} \sum_{i} \beta_{i} d_{\mathrm{p} i} N_{i}$
(Pirjola et al., 1999; Dal Maso et al., 2002), where $d_{\mathrm{p} i}$ is the diameter of the particle in the size class $i$, and $N_{i}$ is the particle number concentration in that size class.

We adopted the transition regime correction factor, $\beta_{m}$, from Fuchs and Sutugin (1971), as follows:

$\beta_{m}=\frac{1+K_{n}}{1+\left(\frac{4}{3} \alpha_{m}+0.337\right) K_{n}+\frac{4}{3} \alpha K_{n}^{2}}$

where $\alpha$ is the sticking coefficient, and $K_{n}$, the Knudsen number, the ratio of two length scales, a length scale $\lambda$ characterising the gas with respect to the transport of mass, and a length scale $d_{\mathrm{p}}$ characterising the particle, is given by $K_{n}=2 \lambda / d_{\mathrm{p}}, \lambda$ being the effective mean free path.

Apart from the condensation sink, the coagulation of ultrafine particles amongst themselves and with larger sized preexisting particles, also limits the total number concentration. For the present case, as described earlier, once the particle burst occurred, there was a substantially rapid drop in the concentration of the particles, with sizes below the Aitken regime which appeared to grow into sizes of Aitken mode and above. A rapid drop also occurred in the total number concentration following the growth, suggesting that "coagulation" was perhaps the dominant process that governed the growth from the ultrafine to the accumulation size regimes. As a large number of small particles must coagulate in order to yield fewer larger particles, a rapid drop in the total number concentration at smaller sizes would occur, even for small increases in the accumulation number concentration as seen in Fig. 3. For a polydisperse aerosol size distribution the coagulation rate depends on the particle size as well as the size spread. Using the equations suggested by Lee and Chen (1984) that were derived by taking into account the effects of both particle size and the size spread of the distribution, we estimated the self-coagulation rate (CR) of the particles. Here, we used different expressions for various Knudsen number regimes, namely, the continuum and gas slip, transition and the free molecule regimes (Lee and 
Chen, 1984; Kim et al., 2003; Chatterjee et al., 1975). The idea behind using both of these near-independent quantities is to find insights into the size transformation via growth kinetics and which can help us to identify the possible dominant growth mechanisms, albeit tentatively, in different size regimes, as well as corresponding changes in the aerosol size distribution and the population.

Figure 5 depicts the strong interplay between these processes and the aerosol population during these events. In Fig. 5a (top panel) the variation in the CS and CR are shown, whereas Fig. 5b (bottom panel) displays the corresponding changes in $N_{\mathrm{t}}$ and the geometrical mean diameter (GMD). The particle burst and growth event periods (events 1 and 2) are identified by the shaded bars. The variation in the number of nucleation particles is reflected in gradual changes seen in GMD.

Prior to event 1 , the CS was in the range of $\sim 0.03-$ $0.08 \mathrm{~s}^{-1}$ (up to 16:00), which dropped to its lowest level $\left(\sim 0.006-0.01 \mathrm{~s}^{-1}\right.$ for the 17:00-18:00 period) at the time of the NPF burst. As the nucleation burst began, large numbers of ultrafine nucleation mode particles were produced, resulting in a sharp increase in the total number concentration (bottom panel) and a corresponding decrease in GMD, which fell sharply from $\sim 170$ to $\sim 25-30 \mathrm{~nm}$. At the same time, the coagulation rate (CR), which prior to the event was $\sim 0.0029 \mathrm{~cm}^{3} \mathrm{~s}^{-1}$ particle ${ }^{-1}$ (up to 16:00), increased sharply following the burst to $0.028 \mathrm{~cm}^{3} \mathrm{~s}^{-1}$ particle ${ }^{-1}$ (10 times higher than earlier values), indicating that the coagulation process was highly active. Thereafter once again the CS increased gradually to reach values of $\sim 0.11-0.14 \mathrm{~s}^{-1}$ (after 19:00), as the continuous supply of freshly formed particles and their instant growth by vapour condensation resulted in a drop in the total number concentration and an increase in the GMD. At the same time, with the size spectrum narrowing, coagulation decreased as the rate of coagulation is positively correlated with the extent of polydispersion. By that time the burst had almost completely ceased. Thereafter, coagulation was the chief controlling process of size transformation. All of these processes were reflected in the observed changes in $N_{\mathrm{t}}$, GMD, and also in $N_{\text {aitk }}$ and $N_{\text {acc }}$ (marked as $A_{1}$ and $\mathrm{AC}_{1}$ in Fig. 3). The result was also evident in the "growth banana" in Fig. 2. During the subsequent period, as the burst weakened and as the coagulation transferred particles to larger sizes, the GMD increased to $\sim 170 \mathrm{~nm}$ and the number concentration dropped to $\sim 3000 \mathrm{~cm}^{-3}$ (by 23:00). The second event at $\sim 01: 00$ resulted in a similar picture, although not as spectacular as the first. Prevailing high RH (may not be the sole factor) and the shallow nocturnal boundary layer capping appears to have supported the fast condensational growth of accumulation particles.

\subsubsection{Growth rates}

During the dynamical state, from the time evolution of the mode diameter $\left(D_{\mathrm{m}}\right)$ for the size distribution, assuming a

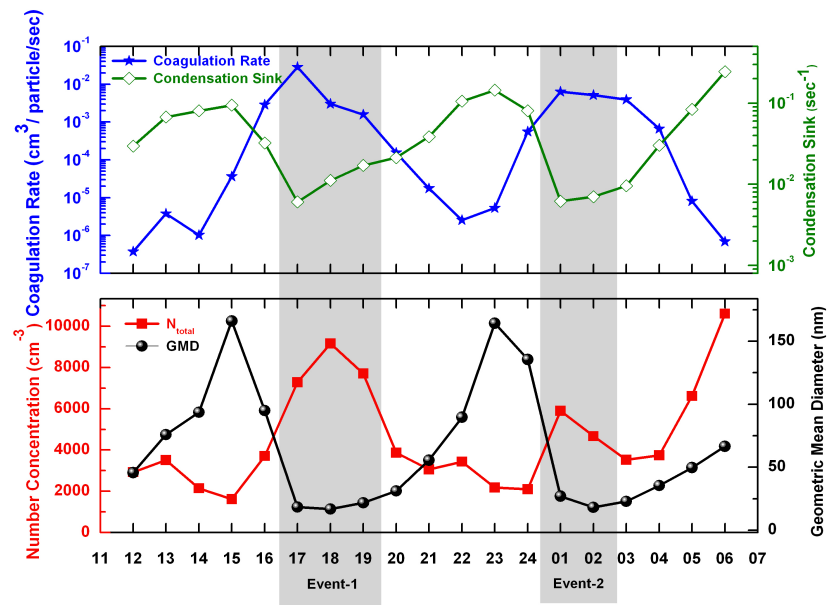

Figure 5. Temporal evolution of the (a) condensation sink (CS) and the coagulation rate (CR) (top panel) and (b) the total aerosol number concentration and the GMD (bottom panel). The shaded portions indicate the events at Trivandrum.

log-normal distribution, the growth rate (GR) was estimated (Fig. 6) (Kulmala et al., 2004; Dal Maso et al., 2005; Wehner et al., 2005). As seen from Fig. 6, the open mode in the nucleation regime associated with NPF began to appear at approximately 16:00 and developed into a well-observed mode at $D_{\mathrm{m}} \sim 22 \mathrm{~nm}$ by $19: 00$, then grew gradually prior to the appearance of the next open mode on the higher side of the detection limit of the instrument, indicating that the mode moved outside of the measurement regime. Throughout the event, the number size distribution predominantly remained unimodal and evolved with time, suggesting a size transformation process. During the next event another open mode in the nucleation regime occurred at approximately $\sim 01: 00$, and subsequently followed a route similar to its predecessor. Using least-squares fitting, the observed NSD to an analytical log-normal size distribution is of the following form:

$$
\begin{aligned}
& \frac{\mathrm{d} N}{\mathrm{~d} \ln D_{\mathrm{p}}}= \\
& \quad \sum_{i=1}^{n} \frac{N_{i}}{\sqrt{2 \pi} \ln \sigma_{\mathrm{m}, i}} \exp \left[-\frac{\left(\ln D_{\mathrm{p}}-\ln D_{\mathrm{m}, \mathrm{p}, i}\right)^{2}}{2 \ln \sigma_{\mathrm{m}, i}}\right],
\end{aligned}
$$

where $D_{\mathrm{p}}$ is the particle diameter, $n$ is the total number of the modes considered, $D_{\mathrm{m}, \mathrm{p}, i}$ is the mode diameter of the $i$ th mode, $\sigma_{\mathrm{m}, i}$ is the corresponding geometric standard deviation of the mode, and $N_{i}$ is the particle number concentration of the $i$ th mode. The mode diameter of the size distribution was estimated as a function of time. From the temporal evolution of the mode diameter, the growth rates (GR) were estimated in the range from 15 to $50 \mathrm{~nm} \mathrm{~h}^{-1}$, from the nucleation to the Aitken mode, when the coagulation apparently dominated. GR values of a similar magnitude have been reported in the literature for urban and coastal locations (Dal Maso et al., 2002; Kulmala et al., 2004; Kulmala and 


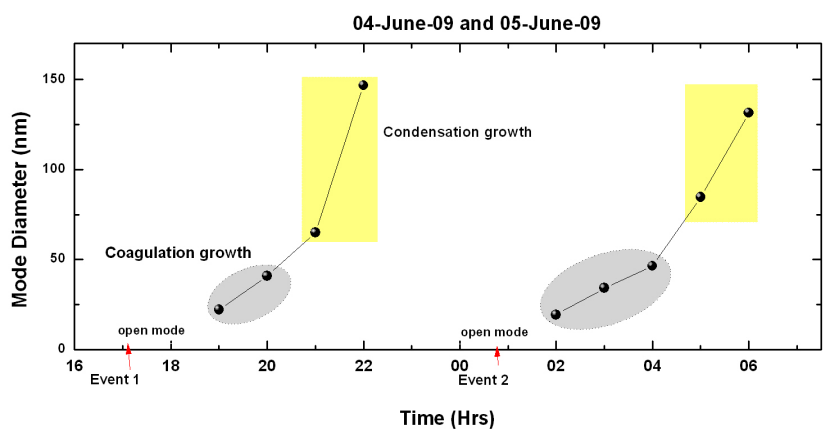

Figure 6. Temporal variation of the mode diameter $\left(D_{\mathrm{m}}\right)$ of hourly mean aerosol number size distribution during the events at Trivandrum. The arrows show the NPF events; grey shaded ovals show the period dominated by the coagulation growth process and yellow shaded rectangles show the periods dominated by condensational growth of the particles.

Kerminen, 2008, and references therein). In the accumulation size regime, the growth of the particle mode at a rate of $>100 \mathrm{~nm} \mathrm{~h}^{-1}$ appeared to be caused by condensational (either due to precursor vapours or hygroscopic ones; this is not known exactly) growth when the size distribution remained nearly the same, but the mode moved to a higher size. Faster growth at larger sizes is in line with condensational processes. Such a result is corroborated by Fig. 5, since the coagulation rate remained quite low during this period. In the accumulation regime, the high $\mathrm{RH}$ and the shallow coastal nighttime boundary layer would further the process. Also, if large amounts of condensable vapours, which can condense over the already formed particles, are present in the atmosphere, the mode of the size distribution would shift to larger sizes, without much change in the total number concentration. The high RH would accelerate the aerosol size transformation process as a result of the condensational growth of hygroscopic particles that could be present at this coastal station, and that may lead to observed sharp nonlinear growth in the accumulation size regime (as also seen in Figs. 2 and 3) with a characteristic "conservation of number concentration" (Shettle and Fenn, 1979). For such cases, the size distribution remains more or less similar with the exception of the mode shifting to larger sizes. Such a feature was observed, as shown in Fig. 4 (middle panel) for 21:00 to 00:00. While as seen by the increasing steepness of the left-hand side of Fig. 4b, it seems that coagulation continued to play a role for the lower (nucleation and Aitken) size regimes. It is worth mentioning here that if hygroscopic growth is dominant, then it has the potential to alter the mixing state of aerosols, their microphysical as well as optical properties, and, hence, aerosol radiative effects (Malm and Kreidenweis, 1997; Kotchenruther et al., 1999; Gasso et al., 2000).

\subsubsection{Possible mechanism for NPF}

Generally, coastal nucleation and growth events occur during daylight hours coinciding with the occurrence of low tide and exposed shorelines, and involve the photo-chemically induced ternary nucleation mechanism of $\mathrm{H}_{2} \mathrm{SO}_{4}, \mathrm{H}_{2} \mathrm{O}, \mathrm{NH}_{3}$ and/or other condensable vapour species of marine origin (shore biota) (O'Dowd et al., 1998a, b, 1999, 2002a; O'Dowd and Hoffmann, 2005, and references therein). Unlike such typical coastal nucleation events associated with "low tide-peak solar radiation during day time" conditions, the present nucleation events were mainly evening nighttime occurrences (the local sunset at 18:00), with subsequent rapid growth to larger sizes. Also, there was no significant tidal activity along the coastline. As such, possible nucleation mechanisms involving the photochemistry of biogenic emissions or the gaseous precursors of marine origin appears to be unimportant. Such a hypothesis is also supported by the observed low concentrations of gaseous $\mathrm{SO}_{2}$, during the entire event, that varied between $\sim 2-4$ ppbv during daytime and $1-2$ ppbv during nighttime, respectively, as revealed from measurements at the same location by another scientific group (I. A. Girach, personal communication, 2011). Most mechanisms of new particle formation reported in the literature primarily involve clusters originating from the nucleation mechanism, mainly involving ubiquitously present sulfuric acid as the major precursor. However, for the present case, such binary or ternary nucleation mechanisms involving $\mathrm{H}_{2} \mathrm{SO}_{4}$ (formed from the oxidation of $\mathrm{SO}_{2}$ ) (O'Dowd et al., 1998a, b; O'Dowd and Hoffmann, 2005) perhaps did not contribute much to the observed "hotspots". The prevalence of an almost invariant $\mathrm{SO}_{2}$ concentration throughout the event, suggests that for the present case, additional "condensable vapour species" may be responsible for the observed nucleation burst. One of the possibilities is the activation of ubiquitous sulfate clusters in a super-saturated organic vapour field that are advected from upwind regions. To examine such possibilities, we reviewed the role of meteorological conditions (Birmili and Wiedensohler, 2000; Pirjola et al., 2000; De Leeuw et al., 2002; O'Dowd et al., 2002a). The five day air mass back-trajectories suggested that air mass arriving at the site were mainly of marine origin, originating from the Arabian Sea. However, coastal nucleation events were less dependent on the air mass origin, and were primarily driven by micro-meteorological influences (De Leeuw et al., 2002).

This tropical coastal location is characterised by a mesoscale sea- and land-breeze circulation system driven by the differential heating of air over the land-ocean, which influences micro-meteorological and boundary layer properties, thereby impacting the aerosol properties (Pillai and Moorthy, 2001, and references therein). By considering local coastline geometry $\left(145-325^{\circ}\right.$ in the azimuth), the sea-breeze component (SBC) of the total wind was estimated as follows: 

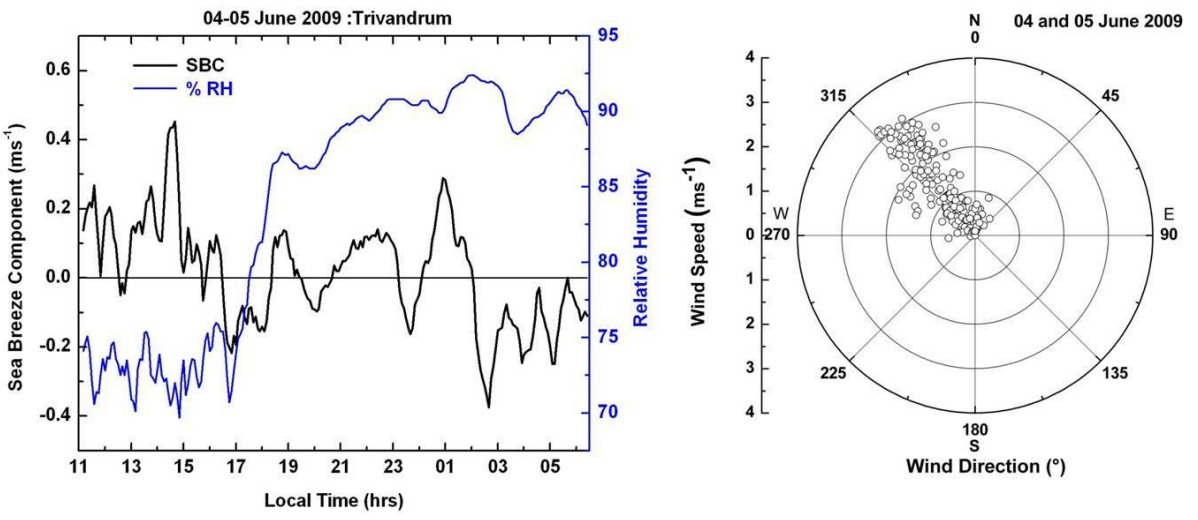

Figure 7. Temporal evolution of the sea breeze component (SBC) and relative humidity (\% RH) for 4-5 June 2009. Positive values of the SBC are representative of onshore flow (sea breeze), while the negative values indicate seaward flow (land breeze). Polar diagram in the right panel shows the total wind speed and wind direction during the period.

$\mathrm{SBC}=\mathrm{WS} \cdot \mathrm{Sin} \cdot(325-\mathrm{WD})$,

where WS is the wind speed $\left(\mathrm{m} \mathrm{s}^{-1}\right)$ and WD is the wind direction (in degrees), measured clockwise from the north. The positive values of the SBC represent onshore flow, while the negative values indicate offshore flow. The SBC along with the relative humidity $(\mathrm{RH})$ during the period is shown in Fig. 7 (the wind pattern during the period is also shown in the right panel of Fig. 7), and reveals that prior to the onset of the first event $(\sim 17: 00)$ the breeze component reversed from positive to negative, indicating an offshore flow directed from the urban landmass. Almost at the same time, the RH increased sharply from $\sim 70$ to $\sim 90 \%$. Offshore flow (from the city) is conducive to brining in urban precursors. As time progressed, the breeze, although low in magnitude, shifted between onshore and offshore flows until approximately midnight. Just prior to the second nucleation event the breeze strengthened somewhat, became offshore again, and continued until morning. Throughout this period the RH hovered around $90 \%$ or more.

These observations support the probability of advection of "condensable vapour species" from the urban area $\sim 8 \mathrm{~km}$ upland. Co-located measurements of $\mathrm{NO}_{\mathrm{x}}$ and $\mathrm{O}_{3}$ (I. A. Girach, unpublished data), which are generally of anthropogenic origin, also displayed a temporal variation with higher values prevailing whenever an offshore breeze prevailed, a pattern similar to that of the aerosol ultrafine number concentration, supporting the idea that precursors of anthropogenic origin were transported to the location by an offshore air mass. Even if the condensable vapour species, brought into the area by offshore flow, were not supersaturated enough for their clusters to nucleate, there is always a possibility that if their abundance were large they could take part in the growth process by interacting with stable clusters formed already (Curtius, 2006). We did not have adequate measurements for identifying the exact composition of the species in the air mass. However, occurrences of similar events under comparable environmental conditions have been reported elsewhere (Stanier et al., 2004; McMurry and Eisele, 2005; Ahlm et al., 2012). Recent studies have also shown that new particle formation during the evening may be possible via the chemical reactions of low volatile organic vapours, involving ozone or $\mathrm{NO}_{\mathrm{x}}$ in the absence of UV and OH (Rissler et al., 2006; Russell et al., 2007; Lee et al., 2008; Zaveri et al., 2010). Wang et al. (2010), based on laboratory experiments, described heterogeneous reactions involving organics that are responsible for the growth of atmospheric nano-particles, while Riipinen et al. (2012) have detailed the importance of the contribution of organic vapours to NPF events and particle growth. New particle production is also reported to be a result of low volatile condensable organics (O'Dowd et al., 2002b) and nighttime oxidants produced as a result of ozonolysis reactions (Lee et al., 2008). During the considerable events covered in our study increases in the concentration of surface $\mathrm{O}_{3}$ and $\mathrm{NO}_{x}$ have been observed, with mean concentrations for ozone and $\mathrm{NO}_{\mathrm{x}}$ $14.54 \pm 3.2 \mathrm{ppb}$ and $7.22 \pm 0.67 \mathrm{ppb}$, during evening, indicating the significant abundance of these trace species (David and Nair, 2011). However, the exact sources and a definite route for NPF could not be identified, as there were no comprehensive and direct gas-phase measurements of the products to identify the mechanism.

Against the backdrop of the above we examine the daytime nucleation event for the Himalayan station Hanle.

\subsection{Case II: Hanle, the high-altitude station}

The formation and evolution of ultrafine particles at highaltitude mountain sites such as Hanle have been attributed to the NPF process through photochemistry in the presence of a significant amount of solar UV radiation, as well as to water vapour/OH during daytime conditions (Moorthy et al., 2011; Kompalli et al., 2012). The strong solar control on 
the process has been brought out over Hanle by Moorthy et al. (2011); however, the observational constraints restricted the measurements largely to daytime hours. With a view to examining the aerosol number size distribution characteristics so as to look for late evening or nighttime nucleation events, a special campaign was conducted during August 2010 when nighttime ambient temperatures were high enough to operate the SMPS $+\mathrm{C}$ instrument. During such measurements, we captured a conspicuous NPF event that occurred from 10 to 12 August 2010. Despite being of shorter duration, the data allowed us to examine the typical features of "nucleation and growth events" at such a high-altitude location. Here also we adopted the criteria prescribed by Dal Maso et al. (2005) for identifying NPF. The five-day isentropic back trajectories arriving at Hanle every two hours during this period (estimated using the HYSPLIT model; https: //ready.arl.noaa.gov/HYSPLIT.php) suggest that the prevailing air masses were westerlies, mostly originating from western Asia and Europe.

In Fig. 8, meteorological conditions during the period are shown. The ambient temperature was generally low $\left(T_{\max } \sim\right.$ $17^{\circ} \mathrm{C}$ around $15: 00$ local time (LT) and $T_{\min } \sim 9^{\circ} \mathrm{C}$ around 06:00 LT) with RH in the range of $28<\mathrm{RH}<75 \%$, characteristic of this high-altitude "cold desert". Wind speeds were considerably high (reaching levels as high as $\sim 15 \mathrm{~m} \mathrm{~s}^{-1}$ ) during the evening hours, while the morning hours experienced calm winds $\left(<2 \mathrm{~m} \mathrm{~s}^{-1}\right)$. The local wind direction varied from northerlies to westerlies/southwesterlies during the course of the day, indicating possible modulation at mesoscale level.

\subsubsection{Number concentrations}

The temporal variation of the aerosol number size distribution (dN/d $\left.\ln D_{\mathrm{p}}\right)$ during the case at Hanle (Fig. 9) depicted a bimodal nature, with the presence of a well-developed accumulation mode that almost remained invariant from 10 to 11 August 2010. A "hot spot" indicating the nucleation burst (an increase in the concentration of nucleation mode particles followed by growth) occurred in the morning hours of $10 \mathrm{Au}-$ gust 2010, and persisted for a period of approximately $2-3 \mathrm{~h}$ until local noon $(\sim 12: 00 \mathrm{LT})$. The nucleation mode gradually grew to Aitken mode, while the accumulation mode remained at approximately the same level until close to midnight, likely representing the aged background distribution at this pristine location. However, from the midnight hours onwards, both of the modes (Aitken and accumulation) began to grow steadily for the next few hours, similar to the "banana-shaped" particle growth (Kulmala et al., 2004). Another such "hotspot" is seen (partly obscured due to a data gap) close to local noon on the next day (11 August 2010). However, there were no fresh nucleation events during the evening or at midnight, with the exception of a very short burst at $\sim 00: 00-03: 00$ on 12 August. In the absence of fresh nucleation events, the particle growth continued into
10-12-August-2010: Hanle
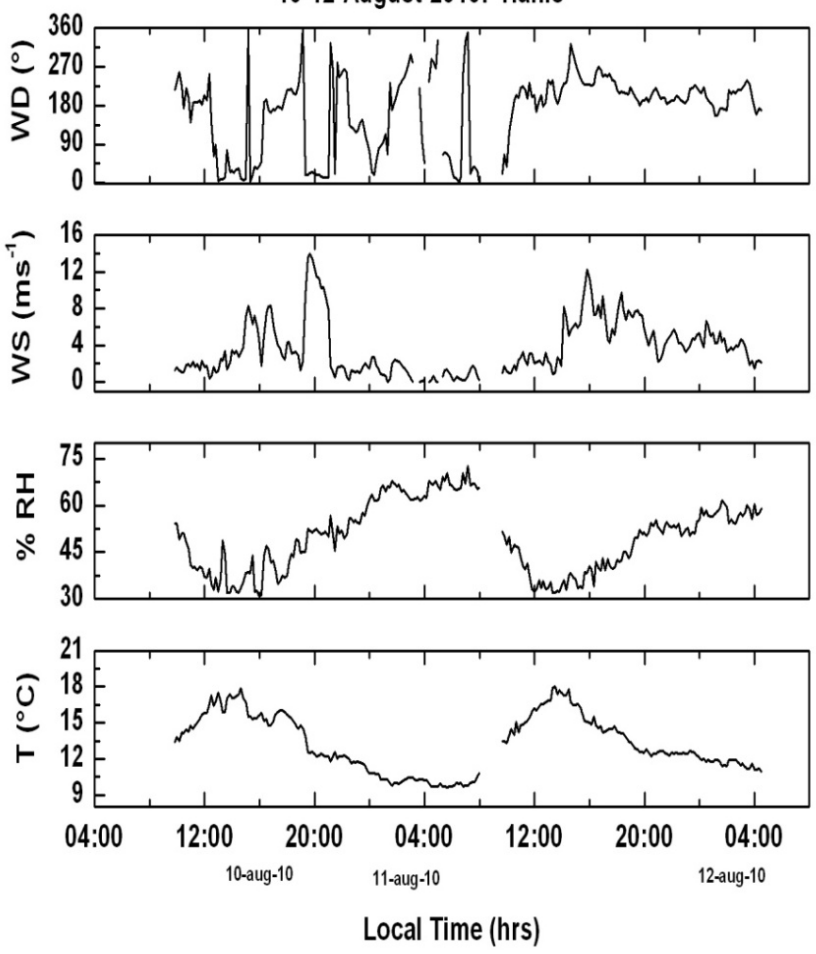

Figure 8. Meteorological conditions at Hanle during the case period (09:50 10 August 2010 to 04:30 12 August 2010 local time) showing low temperature, $\% \mathrm{RH}$ conditions with high winds during afternoon/evening hours and calm winds from midnight to morning hours.

the accumulation mode (in a matter of a few days, as seen at Hanle).

For the two modes observed in the size distribution, the first mode corresponded to fine and ultrafine particles (nucleation and Aitken size ranges), and the second mode in the accumulation mode regime. While the nucleation mode is a resultant of ultrafine particle burst, the fine and accumulation modes could be associated with "cloud processing" that involves multiple condensation-evaporation cycles with modes directly related to the "aqueous phase" history of the air mass. During the entire measurement period from Hanle, the number size distribution revealed a consistent accumulation mode $(115-150 \mathrm{~nm})$ which, perhaps, represents the regional background aerosol. Earlier, Moorthy et al. (2011) made an elaborate discussion on the seasonal variation of the size distributions at Hanle with the help of air mass backtrajectory analysis. Though the air mass trajectories arriving at Hanle during the present study period had a long overpass over dry western Asian regions, the presence of an abundance of clouds over the western and Trans-Himalayan regions during this season (associated with the Asian monsoon in the southern plains) would be conducive to cloud processing. The conspicuous accumulation mode in the size distribution could be due to multiple condensation-evaporation processes 


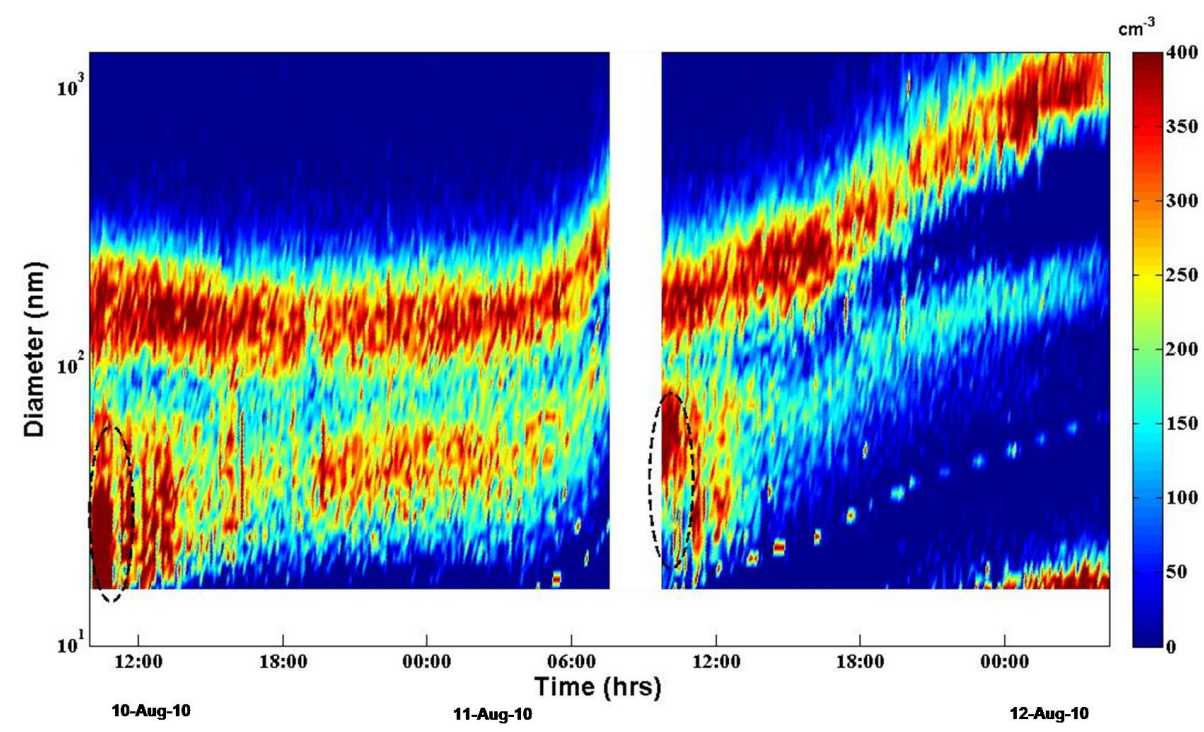

Figure 9. Temporal variation of aerosol number size distribution $\left(\mathrm{d} N / \mathrm{d} \ln D_{\mathrm{p}}\right)$ during the event at Hanle (between 09:50 of 10 August 2010 and 04:30 of 12 August 2010 local time). The white bar indicates a data gap for short durations.

from such cloud cycling (Sellegri et al., 2010). The observation period had quite a few cloud patches passing over the mountaintop observatory. Thus the presence of accumulation size particles is attributed to long-range transport and cloud processing, resulting in particle transformation to these sizes.

Figure 10 provides the aerosol number concentrations the total number concentration $\left(N_{\mathrm{t}}\right)$, the number concentration of the nucleation mode $\left(N_{\text {nuc }}\right)$, the Aitken mode $\left(N_{\text {ait }}\right)$, and the accumulation mode $\left(N_{\mathrm{acc}}\right)$ particles - as a function of time during the episode. The average total number concentration was $\sim 600 \pm 261 \mathrm{~cm}^{-3}$, highlighting the background nature of the location (see Moorthy et al., 2011, for a detailed comparison with other high-altitude sites). The average number concentrations of the particles in different size regimes were $N_{\text {nuc }} \sim 70 \pm 154 \mathrm{~cm}^{-3}, N_{\text {aitk }} \sim 228 \pm 153 \mathrm{~cm}^{-3}$, and $N_{\text {acc }} \sim 302 \pm 60 \mathrm{~cm}^{-3}$. Notably, only $N_{\text {nuc }}$ showed large variation between days and nights, whereas the diurnal variation in $N_{\text {ait }}$ and $N_{\text {acc }}$ remained inconspicuous. While during the day the mean $N_{\mathrm{t}}$ was $\sim 723 \pm 340 \mathrm{~cm}^{-3}$, during the night $N_{\mathrm{t}}$ was $\sim 506 \pm 111 \mathrm{~cm}^{-3}$, suggesting that Hanle was more pristine during the evening as compared to the day. The condition is similar to other such high-altitude locations, with the existence of a "virtual layer" above the temperature inversion where pollutants can reside during daytime, leading to higher daytime concentrations than during the evening when virtually free tropospheric conditions exist (Shaw, 2007). During the nucleation period the $N_{\mathrm{t}}$ and $N_{\text {nuc }}$ values reached values of $\sim 2700$ and $\sim 1500 \mathrm{~cm}^{-3}$, respectively.

\subsubsection{Number size distribution and growth rates}

As seen in Fig. 11, we examined the temporal evolution of the number size distribution. During the nucleation event

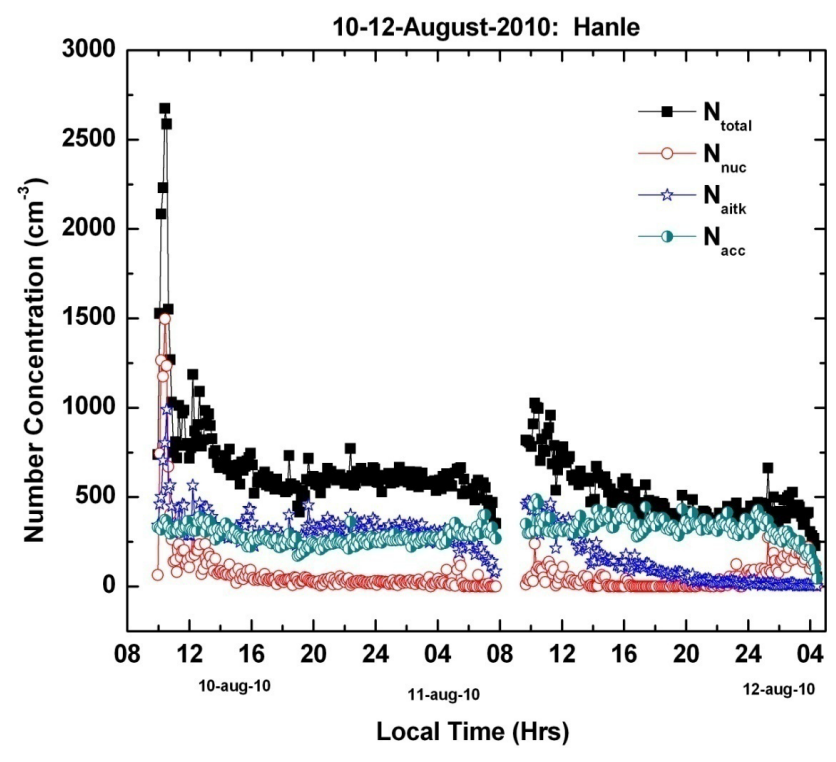

Figure 10. Temporal variation of the aerosol number concentration during the event (between 09:50 of 10 August 2010 to 04:30 of 12 August 2010 local time) at Hanle: total number concentration $\left(N_{\mathrm{t}}\right)$, number concentration of nucleation mode $\left(N_{\text {nuc }}\right)$ (particle diameter $\left.D_{\mathrm{p}}<25 \mathrm{~nm}\right)$, Aitken mode $\left(N_{\text {ait }}\right)\left(25 \mathrm{~nm}<D_{\mathrm{p}}<100 \mathrm{~nm}\right)$ and accumulation mode $\left(N_{\mathrm{acc}}\right)\left(D_{\mathrm{p}}>100 \mathrm{~nm}\right)$ particles.

( $\sim 10: 00$, in both the panels) the NSD exhibits an open mode in the nucleation size regime indicating a large abundance of ultrafine nucleation particles formed at smaller sizes, such that the mode radius would be lower than the lowest size of the DMA classifier measurement range. In due course of time, the size distribution underwent a transformation with 

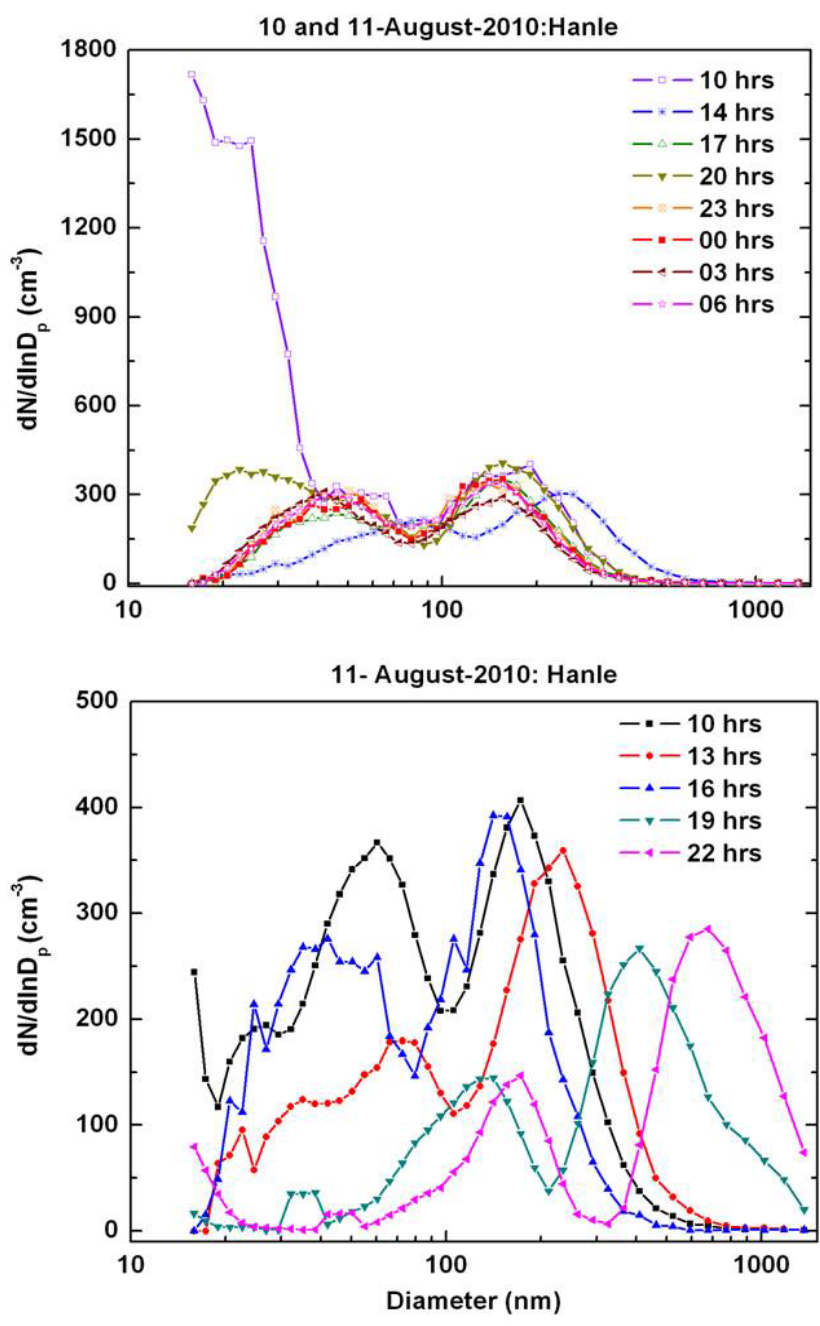

Figure 11. Temporal evolution of hourly mean aerosol number size distribution $\left(\mathrm{d} n / \mathrm{d} \ln D_{\mathrm{p}}\right)$ during the event at Hanle showing an open mode around 10:00 LT, suggesting NPF.

varying modes and such growth dynamics are more discernible in the lower panel of Fig. 11, but the exact mechanism (coagulation or condensation) that brought the changes in size distribution was not conclusively clear and it appears that both coagulation and condensation processes would have contributed to observed changes. By approximating the NSD to analytical bimodal log-normal distribution, mode diameters were estimated both for the modes and the time evolution of the mode diameters are used to infer the growth rates, as for the case with Trivandrum. In primary mode (the nucleation/Aitken mode $\left(D_{\mathrm{p}}<100 \mathrm{~nm}\right)$ regime, the growth rate (GR) from the nucleation to the Aitken mode was found to be in the range of $\sim 0.1$ to $10 \mathrm{~nm} \mathrm{~h}^{-1}$, while from the Aitken to the accumulation mode it was $\sim 10$ to $20 \mathrm{~nm} \mathrm{~h}^{-1}$. In the accumulation size regime growth was more rapid with a GR $>20 \mathrm{~nm} \mathrm{~h}^{-1}$, suggesting that larger particles grew more rapidly, a feature (size dependence on growth rate) also seen at Trivandrum. GR values of similar magnitudes have been reported in the literature from long-term measurements from various high-altitude sites (e.g. Venzac et al., 2008; Boulon et al., 2010; Neitola et al., 2011; Yli-Juuti et al., 2011).

\subsubsection{Possible mechanism for NPF}

The occurrence of the NPF during the daytime is suggestive of the role played by photochemistry (e.g. Venzac et al., 2008). The formation of ultrafine particles a few hours following sunrise is evidence of nucleation resulting from the photochemistry (Lee et al., 2008) of precursor gases (due to the availability of UV at this high-altitude location), also supported by the thermal wind circulation bringing precursor gases to the mountain top from the valley region. It has been shown that mesoscale mountain-valley thermal breeze circulation activity could also influence the diurnal variation of the number concentration (Sellegri et al., 2010; Bonasani et al., 2010). During daytime, upslope winds from the valley region are conducive to bringing pollutants (or precursors) to the mountaintop observatory (as discussed by Weber et al., 1995; Shaw, 2007), whereas down-slope thermal winds during nighttime are capable of removing particles from the top. Recently, Venzac et al. (2008) observed frequent NPF events at $5079 \mathrm{~m}$ a.s.l. in Nepal that could be associated with the mixing of valley air masses with free tropospheric air masses. At Hanle, the availability of precursor gases is likely to be ensured by the strong westerlies that prevailed, which favour advection from the inhabited regions of western Asia, Europe, and the western valley (inhabited) of the TransHimalayas. One interesting aspect that could arise due to such circulation is the inhomogeneity in the mass flux of condensable vapour with time. This is supported by the size dependence of GR. Nucleation began earlier during the day, and by late afternoon growth to larger sizes had taken place with no fresh nucleation. As such, the ambient vapour concentrations may be different for the nucleation period and the growth period.

However, measurements are needed for substantiation of this. The high RH in the late afternoon and evening (Fig. 8b) appears to have set the conditions conducive to an increase in the condensation sink of precursor vapour sources, leading to inhibition of the continuous nucleation mechanism (as suggested by Hamed et al., 2011). This is also supported by the observed rapid growth of the mode diameter in the accumulation size regime, with the total concentration remaining almost invariant (as seen in Fig. 9). Several processes have been proposed in the literature for NPF (Weber et al., 1995, 1999; Kulmala and Kerminen, 2008; Moorthy et al., 2011) at high-altitude locations based on photochemistry that involves the binary or ternary nucleation of gaseous species circulated by thermal winds (e.g. Weingartner et al., 1999; Weber et al., 1999; Shaw, 2007). However, we did not have any measurements of this at Hanle. It is planned to have some in future studies, which might provide better insight into NPF mechanisms. 


\section{Summary and conclusions}

The NPF process in two contrasting environments, a semiurban coastal humid location and a high-altitude one near a pristine dry location, and the subsequent growth to larger sizes by possible coagulation and condensation processes are presented and discussed in this work. From the time evolution of the size distribution during these processes the growth rates in the different size regimes were estimated at both the sites. The main findings were as follows:

1. The late evening/nighttime event at the costal site of Trivandrum resembled an urban-type NPF, with nucleation likely occurring from the mechanism that involved precursors advected from the urban area (though the actual species involved could not be identified) and aided by a mesoscale land-sea breeze circulation that prevailed.

2. The temporal variation in total number concentration $\left(N_{\mathrm{t}}\right)$, the geometric mean diameter (GMD), and the number concentration of the nucleation mode $\left(N_{\text {nuc }}\right)$ suggested that both coagulation of ultrafine particles and the condensation sink (on pre-existing particulars in its accumulation regime) were actively controlling the aerosol size distribution during the event. A rapid increase in the concentration of nucleation mode particles occurred during the NPF bursts. As indicated by the number size distributions, the coagulation process was dominating at sizes below $100 \mathrm{~nm}$ and the NSD underwent rapid changes with the total concentration reducing with time, while possible condensational (due to precursor vapours and/or hygroscopic growth) growth under high RH that prevailed in the coastal boundary layer supported the rapid growth of particle mode diameters in the accumulation regime.

3. The growth rate (GR) values indicated continuous evolution throughout the size spectrum. The estimated GR values were $15 \mathrm{~nm} \mathrm{~h}^{-1}$ in the nucleation regime, $\sim 15$ $50 \mathrm{~nm} \mathrm{~h}^{-1}$ in the Aitken regime, and apparent GR values were $>75 \mathrm{~nm} \mathrm{~h}^{-1}$ in the accumulation size regime, suggesting higher rates as the size increased.

4. In contrast, the daytime nucleation burst at Hanle indicated photochemistry as the possible mechanism for NPF. The mesoscale orographic thermal wind circulation between the valley and the mountain is important at Hanle in influencing the precursor concentrations. Transformation in the number size distribution suggests growth rates in the range of $0.1-10$ and 10$20 \mathrm{~nm} \mathrm{~h}^{-1}$ in the nucleation and Aitken size regimes, respectively, much lower than those for Trivandrum. Even in the accumulation regime, the growth rate was slower $\left(\geq 20 \mathrm{~nm} \mathrm{~h}^{-1}\right)$.
5. The significantly different growth rates between Trivandrum and Hanle could be attributed to the differences in the abundance of precursor concentrations between semi-urban coastal and high-altitude near-pristine environments. It appears that, since particle growth can occur via condensation or coagulation, both of which are particle size-dependent processes, varying growth rates were observed in different size regimes in both environments.

Acknowledgements. The work presented here was a part of the RAWEX field campaign under the ISRO-GBP-ARFI project. We acknowledge Tushar P. Prabhu and the Director, Indian Institute of Astrophysics for providing the facilities necessary to carry out the campaign at Hanle.

Topical Editor P. Drobinski thanks J.-C. Dupont and two anonymous referees for their help in evaluating this paper.

\section{References}

Ahlm, L., Liu, S., Day, D. A., Russell, L. M., Weber, R., Gentner, D. R., Goldstein, A. H., DiGangi, J. P., Henry, S. B., Keutsch, F. N., VandenBoer, T. C., Markovic, M. Z., Murphy, J. G., Xinrong Ren, X., and Scheller, S.: Formation and growth of ultrafine particles from secondary sources in Bakersfield, California, J. Geophys. Res., 117, D00V08, doi:10.1029/2011JD017144, 2012.

Babu, S. S. and Moorthy, K. K.: Anthropogenic impact on aerosol black carbon mass concentration at a tropical coastal station: a case study, Curr. Sci. India, 81, 1208-1214, 2001.

Babu, S. S., Chaubey, J. P., Moorthy, K. K., Gogoi, M. M., Sobhan Kumar Kompalli, Sreekanth, V., Bagare, S. P., Bhatt, B. C., Gaur, V., Prabhu, T. P., and Ningombam, S. S.: High Altitude $(\sim 4520 \mathrm{mamsl})$ measurements of Black Carbon aerosols over Western Himalayas: Seasonal heterogeneity and source apportionment, J. Geophys. Res., 116, D24201, doi:10.1029/2011JD016722, 2011.

Birmili, W. and Wiedensohler, A.: New particle formation in the continental boundary layer: meteorological and gas phase parameter influence, Geophys. Res. Lett., 27, 3325-3328, 2000.

Bonasoni, P., Laj, P., Marinoni, A., Sprenger, M., Angelini, F., Arduini, J., Bonafè, U., Calzolari, F., Colombo, T., Decesari, S., Di Biagio, C., di Sarra, A. G., Evangelisti, F., Duchi, R., Facchini, M. C., Fuzzi, S., Gobbi, G. P., Maione, M., Panday, A., Roccato, F., Sellegri, K., Venzac, H., Verza, G. P., Villani, P., Vuillermoz, E., and Cristofanelli, P.: Atmospheric Brown Clouds in the Himalayas: first two years of continuous observations at the Nepal Climate Observatory-Pyramid (5079 m), Atmos. Chem. Phys., 10, 7515-7531, doi:10.5194/acp-10-7515-2010, 2010.

Boulon, J., Sellegri, K., Venzac, H., Picard, D., Weingartner, E., Wehrle, G., Collaud Coen, M., Bütikofer, R., Flückiger, E., Baltensperger, U., and Laj, P.: New particle formation and ultrafine charged aerosol climatology at a high altitude site in the Alps (Jungfraujoch, $3580 \mathrm{~m}$ a.s.l., Switzerland), Atmos. Chem. Phys., 10, 9333-9349, doi:10.5194/acp-10-9333-2010, 2010.

Chatterjee, A., Kerker, M., and Cooke, D. D.: Brownian coagulation of aerosols in the transition regime, J. Colloid Interf. Sci., 53, 7182, 1975. 
Collins, D. R., Cocker, D. R., Flagan, R. C., and Seinfeld, J. H.: The Scanning DMA Transfer Function, Aerosol Sci. Technol., 38, 833-850, 2004.

Curtius, J.: Nucleation of atmospheric aerosol particles, C. R. Physique, 10, 1027-1045, doi:10.1016/j.crhy.2006.10.018, 2006.

Dal Maso, M., Kulmala, M., Lehtinen, K. E. J., Mäkelä, J. M., Aalto, P., and O'Dowd, C. D.: Condensation and coagulation sinks and formation of nucleation mode particles in coastal and boreal forest boundary layers, J. Geophys. Res., 107, PAR2.1PAR2.10, doi:10.1029/2001JD001053, 2002.

Dal Maso, M., Kulmala, M., Riipinen, I., Wagner, R., Hussein, T., Aalto, P. P., and Lehtinen, K. E. J.: Formation and growth of fresh atmospheric aerosols: eight years of aerosol size distribution data from SMEAR II, Hyytiälä, Finland, Boreal Environ. Res., 10, 323-336, 2005

David, L. M. and Nair, P. R.: Diurnal and seasonal variability of surface ozone and $\mathrm{NO}_{\mathrm{x}}$ at a tropical coastal site: Association with mesoscale and synoptic meteorological conditions, J. Geophys. Res., 116, D10303, doi:10.1029/2010JD015076, 2011.

De Leeuw, G., Kunz, G. J., Buzorius, G., and O’Dowd, C. D.: Meteorological influences on coastal new particle formation, J. Geophys. Res., 107, 8102, doi:10.1029/2001JD001478, 2002.

Fuchs, N. A. and Sutugin, A. G.: Highly dispersed aerosols, in: Topics in current aerosol research, edited by: Hidy, G. M. and Brock, J. R., 422, New York: Pergamon, 1971.

Gasso, S., Hegg, D. A., Covert, D. S., Collins, D., Noone, K. J., Ostrom, E., Schmid, B., Russell, P. B., Livingston, J. M., Durkee, P. A., and Jonsson, H.: Influence of humidity on the aerosol scattering coefficient and its effect on the upwelling radiance during ACE-2, Tellus B, 52, 546-567, 2000.

Hamed, A., Korhonen, H., Sihto, S. L., Joutsensaari, J., Järvinen, H., Petäjä, T., Arnold, F., Nieminen, T., Kulmala, M., Smith, J. N., Lehtinen, K. E. J., and Laaksonen, A.: The role of relative humidity in continental new particle formation, J. Geophys. Res., 116, D03202, doi:10.1029/2010JD014186, 2011.

Helsper, C., Horn, H. G., Schneider, F., Wehner, B., and Wiedensohler, A.: Intercomparison of five mobility particle size spectrometers for measuring atmospheric sub micrometer aerosol particles, Gefahrst Reinhalt Luft, 68, 475-481, 2008.

Holmes, N. S.: A review of particle formation events and growth in the atmosphere in the various environments and discussion of mechanistic implications, Atmos. Environ., 41, 2183-2201, doi:10.1016/j.atmosenv.2006.10.058, 2007.

Kim, D. S., Park, S. H., Song, Y. M., Kim, D. H., and Lee, K. W.: Brownian coagulation of polydisperse aerosols in the transition regime, J. Aerosol Sci., 34-7, 859-868, 2003.

Kompalli, S. K., Sreekanth, V., Chaubey, J. P., Gogoi, M. M., Babu, S. S., Tushar, P. P., and Moorthy, K. K.: Aerosol Number Size Distribution Measurements at Hanle, a Free Tropospheric HighAltitude Site in Western Himalayas, J. Insti. Eng., 8-3, 140-146, 2012.

Kotchenruther, R. A., Hobbs, P. V., and Hegg, D. A.: Humidification factors for atmospheric aerosol off the mid-Atlantic coast of United States, J. Geophys. Res., 104, 2239-2251, 1999.

Krishna Moorthy, K., Suresh Babu, S., and Satheesh, S. K.: Temporal heterogeneity in aerosol characteristics and the resulting radiative impact at a tropical coastal station - Part 1: Microphysical and optical properties, Ann. Geophys., 25, 2293-2308, doi:10.5194/angeo-25-2293-2007, 2007.
Kulmala, M. and Kerminen, V. M.: On the formation and growth of atmospheric nanoparticles, Atmos. Res., 90, 132-150, 2008.

Kulmala, M., Dal Maso, M., Makela, J. M., Pirjola, L., Vakeva, M., Aalto, P., Miikkulainen, P., Hameri, K., and O’Dowd, C. D.: On the formation, growth and composition of nucleation mode particles, Tellus B, 53, 479-490, 2001.

Kulmala, M., Vehkamaki, H., Petaja, T., Dal Maso, M., Lauri, A., Kerminen, V. M., Birmili, W., and McMurry, P. H.: Formation and growth rates of ultrafine atmospheric particles: A review of observation, J. Aerosol Sci., 35, 143-176, 2004.

Lee, K. W. and Chen, H.: Coagulation Rate of Polydisperse Particles, Aerosol Sci. Technol., 3, 327-334, 1984.

Lee, S. H., Young, L. H., Benson, D. R., Suni, T., Kulmala, M., Junninen, H., Campos, T. L., Rogers, D. C., and Jensen, J.: Observations of night-time new particle formation in the troposphere, $\mathrm{J}$. Geophys. Res. 113, D10210, doi:10.1029/2007JD009351 2008.

Malm, W. C. and Kreidenweis, S. M.: The effects of models of aerosol hygroscopicity on the apportionment of extinction, Atmos. Environ., 31-13, 1965-1976, 1997.

McMurry, P. H. and Eisele, F. L.: Preface to topical collection on new particle formation in Atlanta, J. Geophys. Res., 110, D22S01, doi:10.1029/2005JD006644, 2005.

Moorthy, K. K., Sreekanth, V., Chaubey, J. P., Gogoi, M. M., Babu, S. S., Kompalli, S. K., Bagare, S. P., Bhatt, B. C., Gaur, V., Prabhu, T. P., and Singh, S. N.: Fine and ultra fine particles at near free-tropospheric environment over the high altitude station Hanle, in Trans- Himalayas: New particle formation and size distribution, J. Geophys. Res., 116, D20212, doi:10.1029/2011JD016343, 2011.

Neitola, K., Asmi, E., Komppula, M., Hyvärinen, A.-P., Raatikainen, T., Panwar, T. S., Sharma, V. P., and Lihavainen, H.: New particle formation infrequently observed in Himalayan foothills - why?, Atmos. Chem. Phys., 11, 8447-8458, doi:10.5194/acp-11-8447-2011, 2011.

Nishita, C., Osada, K., Matsunaga, K., and Iwasaka, Y.: Numbersize distributions of free tropospheric aerosol particles at Mt. Norikura, Japan: Effects of precipitation and air mass transportation pathways, J. Geophys. Res., 112, D10213, doi:10.1029/2006JD007969, 2007.

O'Dowd, C. D. and Hoffmann, T.: Coastal new particle formation: a review of the current state-of-the-art, Environ. Chem., 2, 245$255,2005$.

O’Dowd, C. D., Geever, M., Hill, M. K., Smith, M. H., and Jennings, S. G.: New particle formation: Nucleation rates and spatial scales in the clean marine coastal environment, Geophys. Res. Lett., 25, 1661-1664, 1998a.

O'Dowd, C. D., Hill, M. K., Smith, M. H., Geever, M., and Jennings, S. G.: New particle formation: Nucleation rates \& spatial scales in the coastal environment, J. Aerosol. Sci., 29, S183S184, 1998b.

O’Dowd, C. D., McFiggans, G., Greasey, D. J., Pirjola, L., Hoell, C., Smith, M. H., Allan, B. J., Plane, J. M. C., Heard, D. E., Lee, J. D., Pilling, M. J., and Kulmala, M.: On the photochemical production of new particles in the coastal boundary layer, Geophys. Res. Lett., 26, 1707-1710, 1999.

O’Dowd, C. D., Aalto, P., Hämeri, K., Kulmala, M., and Hoffmann, T.: Atmospheric particles from organic vapors, Nature, 416, 497 498, 2002a. 
O’Dowd, C. D., Hämeri, K., Mäkelä, J., Väkeva, M., Aalto, P., de Leeuw, G., Kunz, G. J., Becker, E., Hansson, H. C., Allen, A. G., Harrison, R. M., Berresheim, H., Kleefeld, C., Geever, M., Jennings, S. G., and Kulmala, M.: Coastal new particle formation: Environmental conditions and aerosol physicochemical characteristics during nucleation bursts, J. Geophys. Res., 107, 8107, doi:10.1029/2000JD000206, 2002b.

Pillai, P. S. and Moorthy, K. K.: Aerosol mass-size distributions at a tropical coastal environment: Response to mesoscale and synoptic processes, Atmos. Environ., 35, 4099-4112, 2001.

Pirjola, L., Kulmala, M., Bischoff, A., Wilck, M., Bischoff, A., Stratmann, F., and Otto, E.: Formation of sulphuric acid aerosols and cloud condensation nuclei: An expression for significant nucleation and model comparison, J. Aerosol Sci., 30, 1079-1094, 1999.

Pirjola, L., O’Dowd, C. D., Brooks, I. M., and Kulmala, M.: Can new particle formation occur in the clean marine boundary layer?, J. Geophys. Res., 105, 26531-26546, 2000.

Riipinen, I., Yli-Juuti, T., Jeffrey, R. P., Petäjä, T., Douglas, R. W., Kulmala, M., and Neil, M. D.: The contribution of organics to atmospheric nanoparticle growth, Nat. Geosci., 5, 453-458, 2012.

Rissler, J., Vestin, A., Swietlicki, E., Fisch, G., Zhou, J., Artaxo, P., and Andreae, M. O.: Size distribution and hygroscopic properties of aerosol particles from dry-season biomass burning in Amazonia, Atmos. Chem. Phys., 6, 471-491, doi:10.5194/acp6-471-2006, 2006.

Russell, P. B., Livingston, J. M., Redemann, J., Schmid, B., Ramirez, S. A., Eilers, J., Kahn, R., Chu, D. A., Remer, L., Quinn, P. K., Rood, M. J., and Wang, W.: Multi-gridcell validation of satellite aerosol property retrievals in INTEX/ITCT/ICARTT 2004, J. Geophys. Res., 112, D12S09, doi:10.1029/2006JD007606, 2007.

Sellegri, K., Laj, P., Venzac, H., Boulon, J., Picard, D., Villani, P., Bonasoni, P., Marinoni, A., Cristofanelli, P., and Vuillermoz, E.: Seasonal variations of aerosol size distributions based on longterm measurements at the high altitude Himalayan site of Nepal Climate Observatory-Pyramid (5079 m), Nepal, Atmos. Chem. Phys., 10, 10679-10690, doi:10.5194/acp-10-10679-2010, 2010.

Shaw, G. E.: Aerosols at a mountaintop observatory in Arizona, J. Geophys. Res., 112, D07206, doi:10.1029/2005JD006893, 2007.

Shettle, R. W. and Fenn, E. P.: Models for the aerosols of the lower atmosphere and the effects of humidity variations on their optical properties, AFGL-TR-79-0214, Environ. Res. Papers, No. 676, 1979.

Smorodin, V. Y. and Hopke, P. K.: Relationship of heterogeneous nucleation and condensational growth on aerosol nanoparticles, Atmos. Res., 82, 591-604, 2006.

Stanier, C. O., Khlystov, A. Y., and Pandis, S. N.: Nucleation events during the Pittsburgh air quality study: Description and relation to key meteorological, gas phase, and aerosol parameters, Aerosol Sci. Tech., 38, 253-264, 2004.

Suresh Babu, S., Krishna Moorthy, K., and Satheesh, S. K.: Temporal heterogeneity in aerosol characteristics and the resulting radiative impacts at a tropical coastal station - Part 2: Direct short wave radiative forcing, Ann. Geophys., 25, 2309-2320, doi:10.5194/angeo-25-2309-2007, 2007.
Väkevä, M., Hämeri, K., Puhakka, T., Nilsson, E. D., Hohti, H., and Mäkelä, J. M.: Effects of meteorological processes on aerosol particle size distribution in an urban background, J. Geophys. Res., 105, 9807-9821, 2000.

Venzac, H., Sellegri, K., Laj, P., Villani, P., Bonasoni, P., Marinoni, A., Cristofanelli, P., Calzolari, F., Fuzzi, S., Decesari, S., Facchini, M. C., Vuillermoz, E., and Verza, G. P.: High Frequency New Particle Formation in the Himalayas, P. Natl. Acad. Sci., 105-41, 15666-15671, 2008.

Verma, N., Bagare, S. P., Nigombam, S. S., and Singh, R. B.: Aerosol optical properties retrieved using skyradiometer at Hanle in western Himalayas, J. Atmos. Sol. Terr. Phys., 72, 115-124, doi:10.1016/j.jastp.2009.10.016, 2009.

Wang, L., Alexei, F. K., Zheng, J., Xu, W., and Ma, Y.: Vinita Lal and Renyi Zhang: Atmospheric nanoparticles formed from heterogeneous reactions of organics, Nat. Geosci., 3, 238-242, 2010.

Weber, R. J., McMurry, P. H., Eisele, F. L., and Tanner, D. J.: Measurement of expected nucleation precursor species and 3-500 nm diameter particles at Mauna Loa Observatory, Hawaii, J. Atmos. Sci., 52, 2242-2257, 1995.

Weber, R. J., McMurry, P. H., Mauldin, L., Tanner, D., Eisele, F., Clarke, A., and Kapustin, V. N.: New particle production in the remote troposphere: A comparison of observations at various sites, Geophys. Res. Lett., 26, 307-310, 1999.

Wehner, B., Petäjä, T., Boy, M., Engler, C., Birmili, W., Tuch, T., Wiedensohler, A., and Kulmala, M.: The contribution of sulphuric acid and non-volatile compounds on the growth of freshly formed atmospheric aerosols, Geophys. Res. Lett., 32, L17810, doi:10.1029/2005GL023827, 2005.

Weingartner, E., Nyeki, S., and Baltensperger, U.: Seasonal and diurnal variation of aerosol size distributions (10-D-750 nm) at a high alpine site (Jungfraujoch $3580 \mathrm{~m}$ asl), J. Geophys. Res. 104, 26809-26820, 1999.

Winkelmaier, W., Reischl, G. P., Lindner, A. O., and Berner, A.: A new electromobility spectrometer for the measurement of aerosol size distributions in the size range from 1 to $1000 \mathrm{~nm}$, J. Aerosol Sci., 22, 289-296, doi:10.1016/S0021-8502(05)80007-2, 1991.

Yli-Juuti, T., Nieminen, T., Hirsikko, A., Aalto, P. P., Asmi, E., Hõrrak, U., Manninen, H. E., Patokoski, J., Dal Maso, M., Petäjä, T., Rinne, J., Kulmala, M., and Riipinen, I.: Growth rates of nucleation mode particles in Hyytiälä during 20032009: variation with particle size, season, data analysis method and ambient conditions, Atmos. Chem. Phys., 11, 12865-12886, doi:10.5194/acp-11-12865-2011, 2011.

Zaveri, R. A., Berkowitz, C. M., Brechtel, F. J., Gilles, M. J., Hubbe, J. M., Jayne, J. T., Kleinman, L. I., Laskin, A., Madronich, S., Onasch, T. B., Pekour, M. S., Springston, S. R., Thornton, J. A., Tivanski, A. V., and Worsnop, D. R.: Nighttime chemical evolution of aerosol and trace gases in a power plant plume: Implications for secondary organic nitrate and organosulfate aerosol formation, $\mathrm{NO}_{3}$ radical chemistry, and $\mathrm{N}_{2} \mathrm{O}_{5}$ heterogeneous hydrolysis, J. Geophys. Res., 115, D12304, doi:10.1029/2009JD013250, 2010. 